\title{
Artigo Geral 13
}

\section{Fotocatálise do Corante Azul de Metileno por Sistemas como $\mathrm{SrSnO}_{3^{\prime}}, \mathrm{BaSrSnO}_{3}$ e $\mathrm{CaSrSnO}_{3}$}

\author{
Letícia G. Oliveira, Murillo H. M. Rodrigues, Ariadne C. Eduardo, \\ Mario J. Godinho \& Maria R. de C. Santos
}

Com a grande preocupação da população com os problemas ambientais, têm surgido métodos mais eficazes para o tratamento de efluentes. Nesse contexto, surge o estudo sobre a aplicação dos materiais cerâmicos, por exibir propriedades fotocatalíticas como uma alternativa para a descontaminação de corantes em águas residuais. Este trabalho, reportam-se dados da degradação fotocatalítica do corante Azul de Metileno após a adição do catalisador $\mathrm{SnSrO}_{3}$ (antes e após a adição de $0,1 \% \mathrm{Ba}$ e $0,1 \% \mathrm{Ca}$ ). Para tal, amostras foram sintetizados pelo método do Precursor Polimérico, calcinadas à: 500, 800 e 1000 ${ }^{\circ} \mathrm{C} / 4$ horas e caracterizadas por DRX, UV-VIS e fotocatálise.

Palavras-chave: perovskita; estanato; fotocatalisador.

With a major concern of the population about environmental problems, it has more difficult methods to treat for wastewater treatment. In this context, arise or study about the application of ceramic materials by exhibiting photocatalytic properties as an alternative for decontamination of dyes in wastewater. In this work, data on the photocatalytic degradation of the methylene blue dye after the addition of the $\mathrm{SnSrO}_{3}$ catalyst (before and after the addition of $0,1 \%$ to $0,1 \% \mathrm{Ca}$ ) are presented. For this, the samples were synthesized by the polymeric precursor method, calculated at: 500,800 and $1000{ }^{\circ} \mathrm{C} / 4$ hours and characterized by XRD, UV-VIS and photocatalysis.

Keywords: perovskite; stannate; photocatalyst. 


\section{Introdução}

Com o passar dos anos, a utilização de corantes industriais tem aumentado gradativamente e sendo utilizados em pinturas, alimentos, bebidas e roupas. Em indústrias têxteis, o processo de tingimento utiliza grande quantidade de corantes e muita água limpa, que na maioria das vezes, é descartada de forma incorreta. Em função da falta de tratamento destes resíduos, o seu contato com a natureza prejudica, por exemplo, a fotossíntese de plantas e de algas fazendo com que os corantes evitem a passagem de luz para que ocorra o processo de respiração celular ${ }^{1}$.

O azul de metileno é um corante amplamente utilizado na indústria têxtil, derivado de anilina e usado principalmente para tingimento de acrílico, lã, nylon, seda e algodão ${ }^{2}$. Possui fórmula molecular $\mathrm{C}_{16} \mathrm{H}_{18} \mathrm{CIN}_{3} \mathrm{~S} .3 \mathrm{H}_{2} \mathrm{O}$ e peso molecular 373,86 g. $\mathrm{mol}^{-1}$, é classificado como corante básico, pertencente a classe das fenotiazinas. Uma das características dos corantes básicos é que são solúveis em água e produzem cátions coloridos em solução, desta forma, são reconhecidos como corantes catiônicos ${ }^{3,4}$.

\section{PROCESSOS OXIDATIVOS AVANCCADOS (POAs)}

O conceito de POA foi definido por Glace, Kang, e Chapin em 1987. Em geral, é caracterizado por usar espécies excessivamente oxidantes, como o radical hidroxila $\left(\mathrm{OH}^{-}\right)$, que favorece degradação do poluente podendo ser mineralizado em $\mathrm{CO}_{2}$, água e ânions inorgânicos. POAs são processos não seletivos, ou seja, que degradam todos os compostos que estão no meio ${ }^{5}$, motivo que o torna amplamente utilizado para o tratamento de diferentes efluentes contaminados com substâncias difíceis de serem degradadas pelos tratamentos convencionais ${ }^{6}$.

Os radicais hidroxila são gerados a partir de reações com oxidantes fortes, como ozônio $\left(\mathrm{O}_{3}\right)$, peróxido de hidrogênio $\left(\mathrm{H}_{2} \mathrm{O}_{2}\right)$ ou por semicondutores sintéticos metálicos, tais como: $\mathrm{TiO}_{2}, \mathrm{ZnO}, \mathrm{SrSnO}_{3}$, entre outros, na presença da radiação UV. Os radicais hidroxilas reagem com os compostos orgânicos presentes no meio resultando radicais orgânicos, que por sua vez, reagem com o oxigênio presente provocando a quebra de compostos orgânicos ${ }^{7}$. Na literatura, existem vários processos para a formação desses radicais e, uma forma muito citada, é pela fotocatálise heterogênea.

\section{FOTOCATÁLISE HETEROGÊNEA}

No processo de fotocatálise heterogênea, têm-se semicondutores, como catalisadores na fase sólida, e a reação química ocorre na área de interação entre as duas fases. A velocidade depende de diversos fatores, sendo os principais, a área superficial de contato e a concentração do material ${ }^{7}$. Esses semicondutores são ativados através da luz solar ou luz artificial, provocando uma transição eletrônica. No esquema abaixo, é ilustrado o processo de fotoativação de um semicondutor.

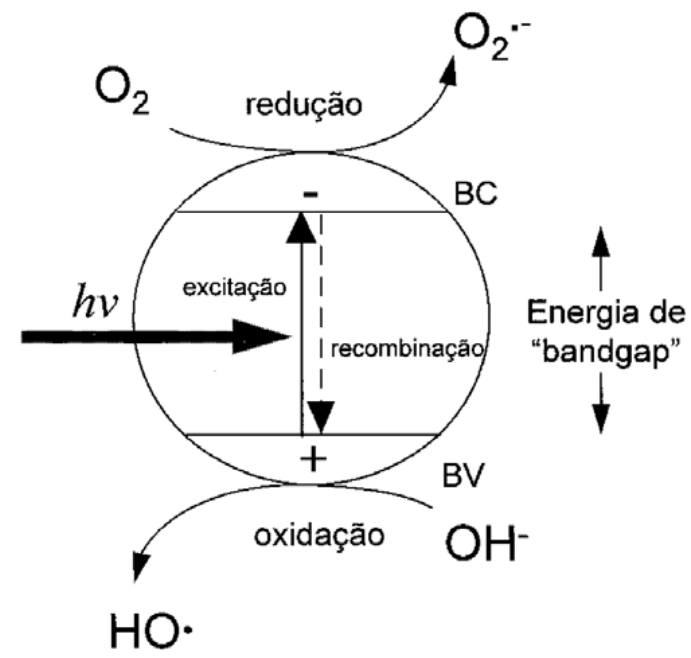

Figura 1. Esquema representativo da foto-ativação de semicondutor; BV: Banda de Valência, BC: Banda de condução. Fonte: Teixeira $(2004)^{8}$.

No processo representado na Figura 1, os elétrons são excitados através da luz e são promovidos da banda de valência para a banda de condução, ocorrendo a geração de sítios oxidantes e redutores capazes de catalisar as reações químicas, oxidando os compostos orgânicos. Quando isso ocorre, a região entre as duas bandas é chamada de band gap ${ }^{8,9}$.

Nessa degradação, as moléculas de água adsorvidas na interface do material, reagem com as lacunas formados na banda de valência, geram-se os radicais hidroxilas, 
fortemente reativos e que podem reagir com as moléculas orgânicas presentes no meio. Já os oxigênios presentes no meio podem reagir com os elétrons na banda de condução produzindo $\mathrm{O}^{2-}$, que é uma espécie reativa, podendo assim oxidar mais compostos orgânicos ${ }^{10}$. Assim, fotocatalisador ideal será aquele que viabilizará os dois processos que ocorrem simultaneamente.

\section{PEROVSQUITA}

Descoberta em 1830, o mineral perovsquita apresenta estrutura encontrada em diversos materiais ${ }^{11}$. Considerado um material isomérico relativamente raro pode ser encontrado na forma tetragonal, ortorrômbica, romboédrica, monoclínica e cúbica. Formas estruturais do tipo $\mathrm{ABO}_{3}$, geralmente materiais cerâmicos combinados com elementos não metálicos, em que A é um cátion metálico mono, di ou trivalente. B é um cátion metálico tri, tetra ou pentavalente como, por exemplo: Ti, Sn, Zr, e o oxigênio.

$\mathrm{Na}$ Figura 2, representa-se a imagem de uma estrutura do tipo perovsquita.

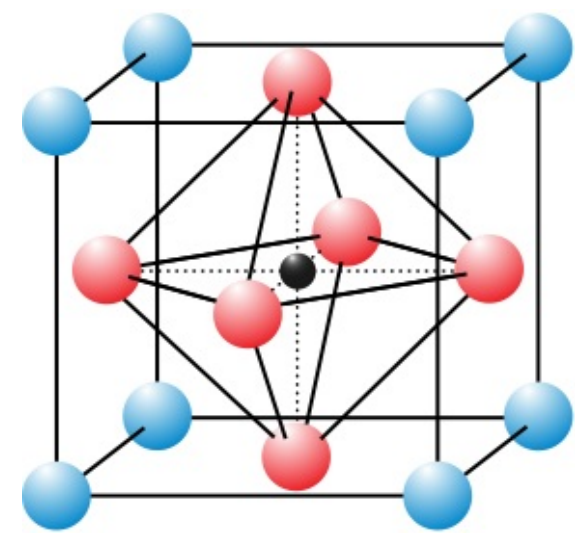

Figura 2. Esquema genérico de perovskita, do tipo $\mathrm{ABO}_{3}$. Fonte: Santos $(2015)^{12}$.

As distorções em sua rede cristalina podem ser causadas devido a elementos maiores alocados em A e $\mathrm{B}$, por concentrações diferentes ou adição de impurezas. As distorções ocorridas nos octaedros e dodecaedros produzem importantes mudanças e surgimento de novas propriedades elétricas e estruturais que instigam grande interesse tecnológico e científico ${ }^{12,13}$.

Dentre as perovsquitas mais estudas na literatura, destacam-se os estanato de estrôncio $\left(\mathrm{SrSnO}_{3}\right)$. Estudos revelam que o $\mathrm{SrSnO}_{3}$ altera sua estrutura de ortorrômbica para tetragonal e posteriormente para cúbica em função da variação de temperatura e/ou pela presença de impurezas no material ${ }^{12}$. A inserção de impurezas é comumente utilizada para promover defeitos estruturais e/ou eletrônicos, visando ao surgimento de novas propriedades e/ou melhorias no sistema ${ }^{11-13}$.

No trabalho proposto, investigou-se o processo de fotodegradação do corante azul de metileno, em solução aquosa, por processo de fotocatálise heterogênea, utilizando como fotocatalisador o estanato de estrôncio puro e dopado com $1 \%$ de bário e $1 \%$ de cálcio, em diferentes temperaturas de tratamento térmico, para verificar a influência da temperatura e das impurezas na fotocatálise de cada material.

\section{Experimental}

\section{SÍNTESE}

Os materiais $\mathrm{SrSnO}_{3}, \mathrm{CaSrSnO}_{3}$ e $\mathrm{BaSrSnO}_{3}$ foram obtidos pelo Método dos Precursores Poliméricos ${ }^{14}$. As dopagens foram realizadas com $1 \%$ em mol $\mathrm{Ca}$ ou $1 \%$ em mol de Ba. Após a obtenção do "puff", esse foi desaglomerado e submetido a tratamento térmico em forno tipo mufla, nas temperaturas de 500,800 e $1000^{\circ} \mathrm{C}$, durante 4 horas. Em seguida, os pós obtidos foram caracterizados por Difração de Raios X e Espectroscopia de UV-VIS. Posteriormente, foram realizados os testes fotocatalíticos.

\section{FOTOCATÁLISE}

A avaliação da degradação fotocatalítica das amostras foi realizada em um reator de bancada contendo uma lâmpada de mercúrio (fonte UV) empregada como fonte de radiação para o monitoramento de degradação do corante azul de metileno. Para a análise, preparou-se uma solução aquosa contendo o corante na concentração de $200 \mathrm{mg} / \mathrm{L}$, a 
qual foi transferida para o reservatório do sistema. Todo o processo ocorreu em um reator, representado por um sistema fechado, contendo um recipiente reacional, alimentado por uma bomba de arraste magnético para a recirculação da solução, (sob vazão controlada-rotâmetro) e termostatizada (via trocador de calor). A agitação do meio para manter o catalisador em suspensão ocorre por agitador magnética.

O processo de fotocatálise foi otimizado, avaliando-se os seguintes parâmetros: a temperatura de calcinação do catalisador e o material contendo impurezas. A solução do corante foi colocada dentro do reator fotoquímico com $300 \mathrm{~mL}$ de água destilada, resultando em 3,2 mg/L de concentração. Um valor médio de $30 \mathrm{mg}$ das amostras é colocado em ponteiro ultrassom para total dispersão. Posteriormente, o sistema catalítico é adicionado à solução de azul de metileno.

Dentro do reator, a solução de catalisador/corante são expostos à luz do equipamento. Os ensaios foram realizados a partir de alíquotas de aproximadamente $4 \mathrm{~mL}$ retiradas em tempos regulares de: $0,5,10,20,40,60,80,100$ e 120 min. As quais são posteriormente centrifugadas por $5 \mathrm{~min}$, com rotação de 4000 rpm, a fim de separar o pó catalisador (amostra) da solução. A análise da solução obtida ocorre em um espectrofotômetro UV-Vis de bancada. O percentual de descolaração do corante foi calculado com base nos valores de absorbância da banda em 664 nm que, de acordo com a literatura, é onde há o maior comprimento de onda ${ }^{15,16}$.

\section{Resultados e Discussão}

Todas as amostras de sintetizadas de $\mathrm{SrSnO}_{3}, \mathrm{CaSrSnO}_{3}$ e $\mathrm{BaSrSnO}_{3}$ foram caracterizadas inicialmente por Difração de raios $\mathrm{X}$, para a identificação das fases obtidas. As amostras apresentaram mais de uma estrutura cristalina, ou seja, uma mistura de fases $\mathrm{SrSnO}_{3}, \mathrm{SnO}_{2}$ e $\mathrm{SrCO}_{3}$, sendo indexadas pelas Fichas Cristalográficas JCPDS: 01-074-1298, 00-0211250, 00-001-0556, respectivamente. Contudo, observa-se a estrutura perovskita como fase majoritária/predominante, e como fase secundária o carbonato de estrôncio $\left(\mathrm{SrCO}_{3}\right)$ e o óxido de estanho $\left(\mathrm{SnO}_{2}\right.$, rutilo).

A Figura 3 ilustra o difratograma do $\mathrm{SrSnO}_{3}$, nota-se que a $500{ }^{\circ} \mathrm{C}$, o material apresenta desordem estrutural, ou seja, ordem estrutural a curto alcance. Observa-se que o aumento da temperatura de calcinação, para 800 e $1000^{\circ} \mathrm{C}$, leva à diminuição de níveis intermediários, ocasionado o aumento da organização estrutural e a cristalinidade do material ${ }^{17-19}$. Nota-se que com o aumento da cristalinidade há aumento da intensidade dos picos de difração e seu estreitamento.

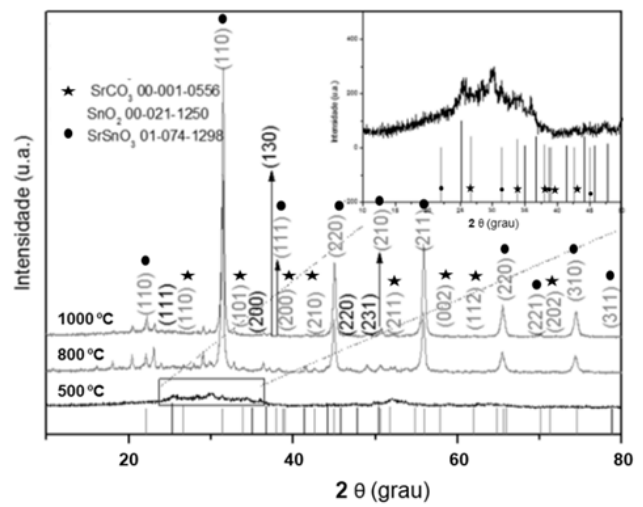

Figura 3. Difratogramas de raios $\mathrm{X}$ para $\mathrm{SrSnO}_{3}$ obtidos em função da temperatura de calcinação das amostras $\left(500800\right.$ e $\left.1000^{\circ} \mathrm{C}\right)$.

A Figura 4 ilustra o difratograma do $\mathrm{SrSnO}_{3}$ dopado com $1 \%$ de bário. Nota-se que a amostra tratada termicamente a $500{ }^{\circ} \mathrm{C}$ apresenta a maioria dos picos dos materiais tratados termicamente a 800 e $1000{ }^{\circ} \mathrm{C}$, porém com baixa intensidade.

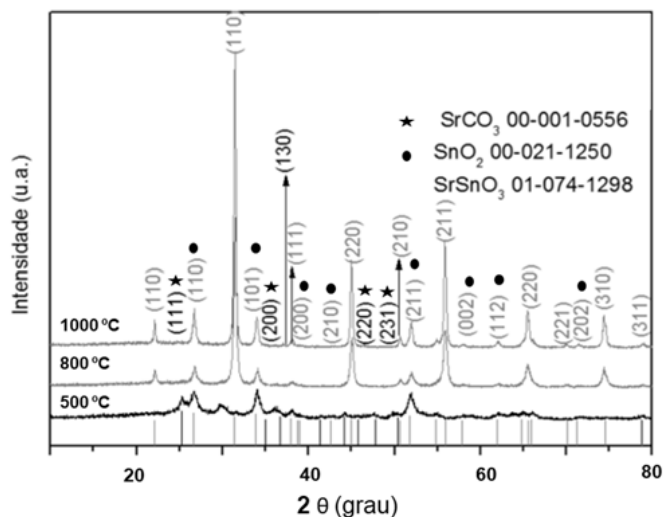

Figura 4. Difratogramas de raios $\mathrm{X}$ para $\mathrm{SrSnO}_{3}$ dopado com $1 \%$ de bário obtidos em função da temperatura de calcinação das amostras $\left(500800\right.$ e $\left.1000^{\circ} \mathrm{C}\right)$. 
A Figura 5 ilustra o difratograma do $\mathrm{SrSnO}_{3}$ dopado com $1 \%$ de cálcio. Observa-se que a $500{ }^{\circ} \mathrm{C}$ o material apresenta desordem estrutural, conforme observado para o $\mathrm{SrSnO}_{3}$, sem adição de dopante.

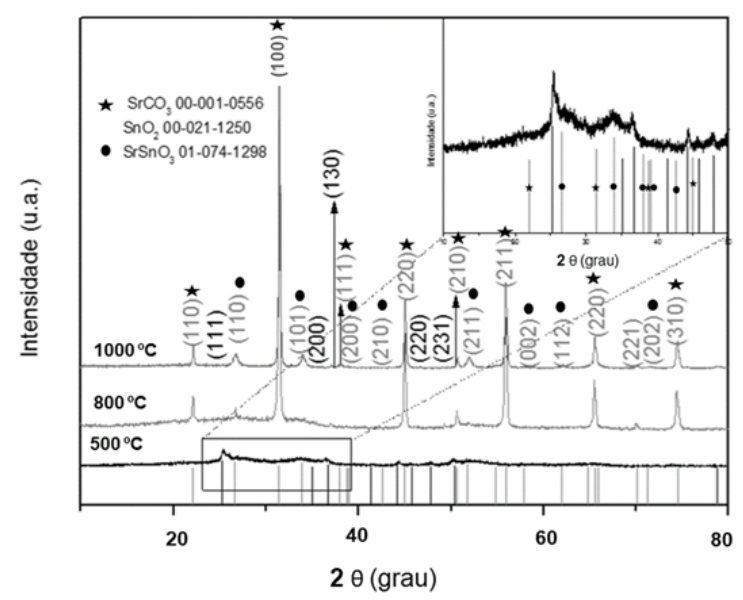

Figura 5. Difratogramas de raios $\mathrm{X}$ para $\mathrm{SrSnO}_{3}$ dopado com $1 \%$ de cálcio obtidos em função da temperatura de calcinação das amostras $\left(500800\right.$ e $\left.1000^{\circ} \mathrm{C}\right)$.

$\mathrm{Na}$ Figura 5, é possível citar que a adição de cálcio (raio iônico 0,99 A) em substituição ao estrôncio (raio iônico $1,18 \AA$ ) ocasiona aumento do grau de cristalinidade da matriz de $\mathrm{SrSnO}_{3}$ a 800 e $1000{ }^{\circ} \mathrm{C}$, sendo observados picos de difração mais intensos e estreitos, logo a impureza gera maior organização no sistema. Avaliando esta afirmação em números, foram calculados os valores de largura à meia altura e o tamanho de cristalito para as amostras (antes e após a adição de impureza), conforme ilustrado na Tabela 1:

Tabela 1. Largura à meia altura por tamanho de cristalito para os materiais $\mathrm{SrSnO}_{3}, \mathrm{BaSrSnO}_{3}$ e $\mathrm{CaSrSnO}_{3}$.

\begin{tabular}{|c|c|c|c|}
\hline \multirow{2}{*}{ Materiais } & \multicolumn{3}{|c|}{$\mathrm{FWHM} / \mathrm{TC}(\mathrm{nm})$} \\
\cline { 2 - 4 } & $\mathbf{5 0 0}^{\mathbf{}} \mathbf{C}$ & $\mathbf{8 0 0}^{\mathbf{}} \mathbf{C}$ & $\mathbf{1 0 0 0}^{\mathbf{}} \mathbf{C}$ \\
\hline $\mathbf{S r S n O}_{\mathbf{3}}$ & $3,8645 / 2,126$ & $0,2794 / 36,238$ & $0,2626 / 39,896$ \\
\hline $\mathbf{B a S r S n O}_{3}$ & $0,8725 / 9,525$ & $0,3557 / 26,050$ & $0,2344 / 48,662$ \\
\hline $\mathbf{C a S r S n O}_{3}$ & $0,3841 / 23,378$ & $0,1954 / 75,338$ & $0,1906 / 81,95$ \\
\hline
\end{tabular}

No geral, as amostras contendo impurezas apresentam resultados com menores valores de FWHM indicando que a substituição do $\mathrm{Sr} \rightarrow \mathrm{Ca}$ ou Ba promove maior organização a longo alcance, e maiores valores do tamanho de cristalito, o que deve estar atribuído a um aumento nos processos de difusão, como consequência da menor distorção na rede.

A amostra contendo $1 \% \mathrm{em} \mathrm{mol} \mathrm{de} \mathrm{cálcio} \mathrm{apresentou}$ maiores valores do tamanho de cristalino. Estes resultados intrínsecos da matéria são fundamentais para compreensão dos resultados na fotocatálise. Ao comparar a mesma amostra em função da temperatura de calcinação, observase o decréscimo dos valores de FWHM, que ocorre gradativamente com o aumento da temperatura, indicando que amostras de 800 e $1000{ }^{\circ} \mathrm{C}$ possuem uma maior organização. Resultado este que também pode ser observado pela análise gráfica do pico de difração de $100 \%$, que se torna cada vez mais estreito com a temperatura. O tamanho de cristalito também aumenta com a temperatura, ou seja, em maiores temperaturas a rede cristalina sofre menores distorções apresentando-se mais ordenada e mais cristalina.

Os testes de fotocatálise foram realizados para $300 \mathrm{~mL}$ de efluente simulado que continham $3,2 \mathrm{mg} / \mathrm{L}$ de corante azul de metileno e $30 \mathrm{mg}$ do catalisador em solução aquosa. Das soluções, antes da lâmpada ser ligada, foi retirada alíquota de 4,0 mL para a verificação de autodegradação. Uma segunda alíquota das soluções com o catalisador, mantidas no sistema por $5 \mathrm{~min}$. escuro, foi retirada para estabilização. Em seguida, retiradas outras alíquotas de 4,0 mL nos tempos de: 0, 5, 10, 20, 40, 60, 80, 100 e 120 min.; a fim de verificar a atividade fotocatalítica em função do tempo. Para as amostras sob incidência de luz foi observado à descoloração das amostras em função do tempo de exposição à luz de forma progressiva. Assim foi avaliado o efeito fotocatalítico desses materiais. Os resultados da fotocatálise realizada para amostras de $\mathrm{SrSnO}_{3}$ em função temperatura de calcinação são apresentados na Figura 6.

Nota-se pela Figura 6 que a melhor resposta de degradação foi a amostra tratada termicamente a $500{ }^{\circ} \mathrm{C}$, a qual pela Difração de raios $\mathrm{X}$ apresentou fases secundárias e baixa cristalinidade, sendo observada pela falta de definição dos picos de difração (intensidade), correspondentes aos planos cristalinos de cada plano cristalino. A baixa cristalinidade das estruturas é uma forte evidência da 
presença de defeitos estruturais e, até mesmo eletrônicos, que se mostraram importantes para esse processo de degradação fotocatalítica. Quando a amostra foi submetida a $800{ }^{\circ} \mathrm{C}$, teve como predominância a formação da estrutura perovskita $\mathrm{SrSnO}_{3}$ com alta cristalinidade, porém com presença de fases secundárias, assim como observado também a $500{ }^{\circ} \mathrm{C}$. Porém, tanto a proporção de fases desta amostra, quanto a sua cristalinidade são responsáveis por gerar defeitos deletérios ao processo fotocatalítico do azul de metileno. No entanto, o aumento da temperatura de tratamento térmico das amostras para $1000{ }^{\circ} \mathrm{C}$ já promove a inversão do resultado observado a $800{ }^{\circ} \mathrm{C}$. No qual se observam melhores valores de fotodegradação das amostras.
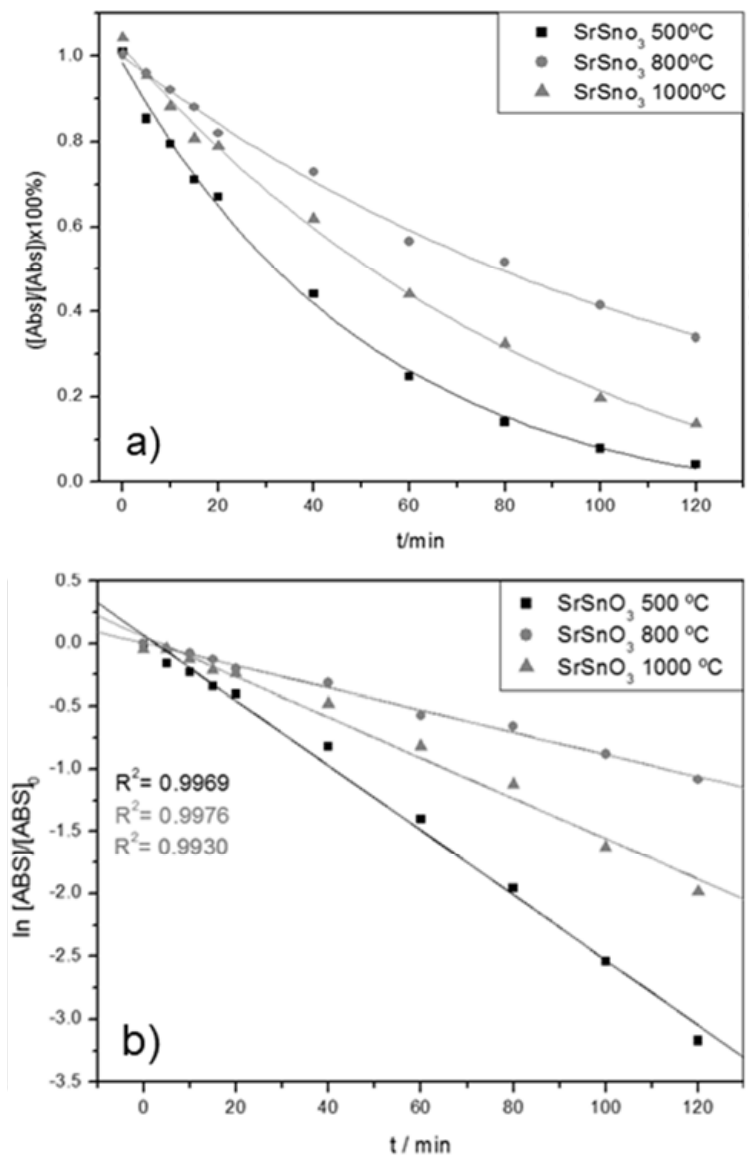

Figura 6. (a) Fotodegradação de $\mathrm{SrSnO}_{3}$ em diferentes temperaturas; (b) cálculo da constante da velocidade, reação de pseudo $1^{\mathrm{a}}$ ordem.
A melhoria na fotodegradação pode ser explicada pelo decréscimo da concentração das fases secundárias. Mostrando o quão importante são as fases secundárias para a resposta catalítica do sistema em estudo. A constante de velocidade segue a reação da pseudo de $1^{\text {a }}$ ordem, com $\mathrm{R}^{2}$ maior que 0,9 , e a porcentagem de degradação estão ilustrada na Tabela 2.

Tabela 2. Porcentagem de degradação $\mathrm{SnSrO}_{3}$ e constantes de velocidade.

\begin{tabular}{|c|c|c|c|}
\hline & \multicolumn{3}{|c|}{$\mathrm{SnSrO}_{3}$} \\
\hline Fotocatalisador & $500{ }^{\circ} \mathrm{C}$ & $800{ }^{\circ} \mathrm{C}$ & $1000{ }^{\circ} \mathrm{C}$ \\
\hline$\%$ de descoloração & 95,84 & 66,27 & 86,84 \\
\hline $\mathrm{K}\left(\mathrm{min}^{-1}\right)$ & 0,031 & 0,012 & 0,013 \\
\hline
\end{tabular}

$\mathrm{Na}$ Figura 7 são apresentados os resultados de descoloração obtidos para as amostras de $\mathrm{SrSnO}_{3}$ contendo $1 \%$ de bário em função das temperaturas de calcinação.

De acordo com a Figura 7, observa-se o decréscimo do processo de degradação do corante (quebra da ligação do grupo cromóforo), nos três fotocatalisadores. Para estas amostras foram calculadas as porcentagens de fotodegradação, bem como as constantes de velocidade, as mesmas estão ilustradas na Tabela 3.

Tabela 3. Porcentagem de degradação $\mathrm{BaSnSrO}_{3}$ e constantes velocidade.

\begin{tabular}{|c|c|c|c|}
\hline & \multicolumn{3}{|c|}{$\mathrm{BaSnSrO}_{3}$} \\
\hline Fotocatalisador & $\mathbf{5 0 0}^{\mathbf{}} \mathbf{C}$ & $\mathbf{8 0 0}^{\mathbf{}} \mathbf{C}$ & $\mathbf{1 0 0 0}^{\mathbf{}} \mathbf{C}$ \\
\hline \% de descoloração & 89,62 & 89,40 & 90,63 \\
\hline $\mathrm{K}\left(\mathbf{m i n}^{-1}\right)$ & 0,0125 & 0,014 & 0,015 \\
\hline
\end{tabular}

No reator, a eficiência foi muita próxima com as três concentrações de catalisadores realizadas, no entanto, a que obteve uma maior eficiência foi $\mathrm{BaSrSnO}_{3} 1000{ }^{\circ} \mathrm{C}$, apresentando a remoção de $90,63 \%$ em 120 minutos. Aadição de bário ao sistema de $\mathrm{SrSnO}_{3}\left(800\right.$ e $1000{ }^{\circ} \mathrm{C}$ ) promove um melhor resultado fotocatalítico, sendo de 66/86\% para o $\mathrm{SrSnO}_{3}$, contra $90 \%$ para a amostra de $\mathrm{BaSrSnO}_{3}$, aproximadamente. Para as amostras de 800 e $1000{ }^{\circ} \mathrm{C}$ tem-se maior cristalinidade das fases secundárias de $\mathrm{SnO}_{2} \mathrm{e} \mathrm{SrSnO}_{3}$, não se apresentam grandes diferenças entre ambos, o que 
explica os valores próximos frente à fotocatálise do azul de metileno. Com base na cinética química da reação, ambas reações seguem uma pseudo $1^{\mathrm{a}}$ ordem.
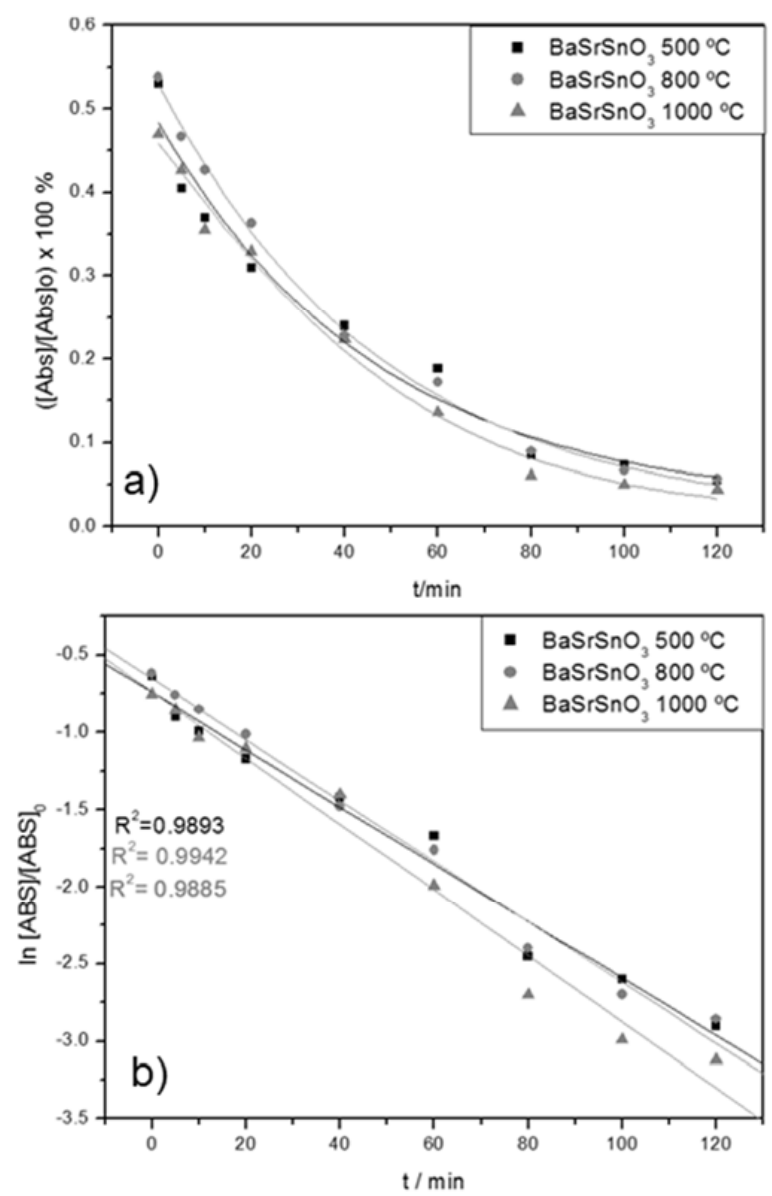

Figura 7. (a) Fotodegradação de $\mathrm{BaSrSnO}_{3}$ em diferente temperaturas; (b) cálculo da constante da velocidade, reação de pseudo $1^{\mathrm{a}}$ ordem.

NaFigura 8, são apresentados os resultados de descoloração obtidos para as amostras de $\mathrm{SrSnO}_{3}$ após a adição de $1 \%$ de cálcio em função da temperatura de calcinação.

$\mathrm{Na}$ Figura 8, observa-se que a absorbância das amostras decresce, mostrando uma ótima descoloração na cor. Foi calculada a porcentagem de fotodegradação e a constante de velocidade para cada uma das amostras, como demostrado na Tabela 4.
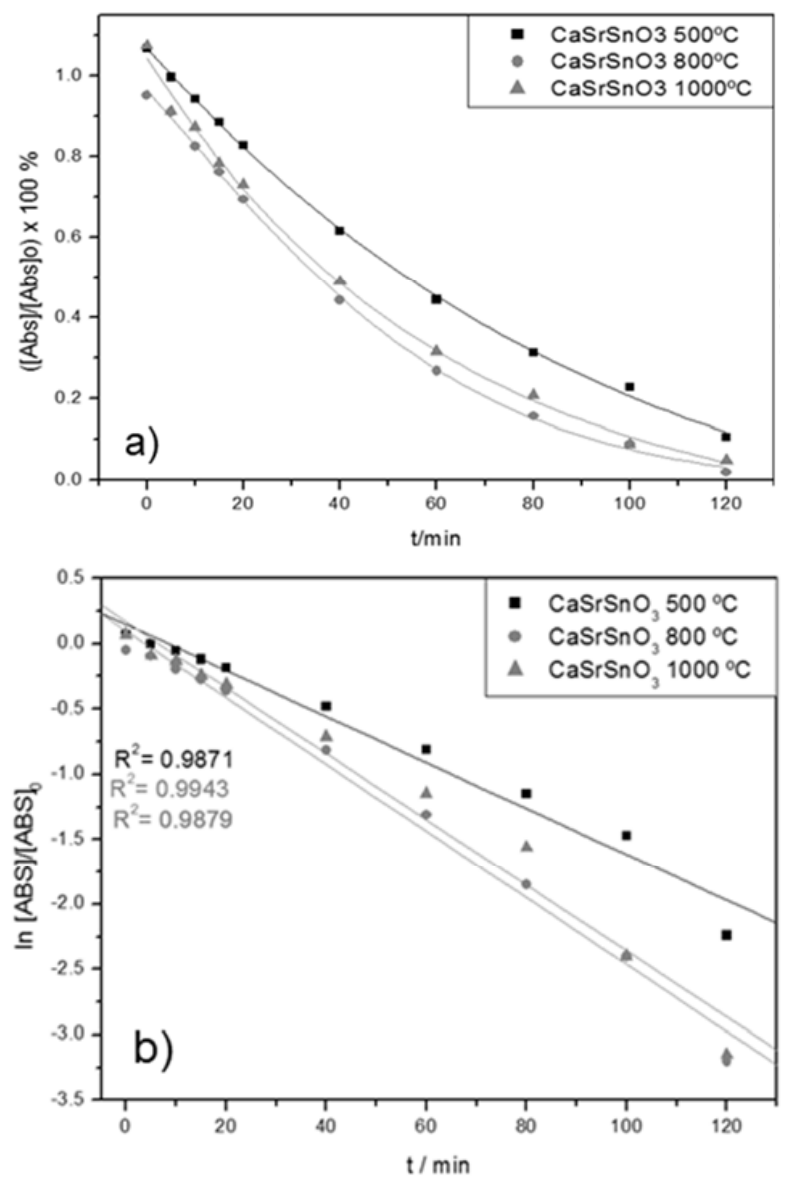

Figura 8. (a) Fotodegradação de $\mathrm{CaSrSnO}_{3}$ em diferente temperaturas; (b) cálculo da constante da velocidade, reação de pseudo $1^{\mathrm{a}}$ ordem.

Tabela 4. Porcentagem de degradação $\mathrm{CaSrSnO}_{3}$ e constantes velocidade.

\begin{tabular}{|c|c|c|c|}
\hline & \multicolumn{3}{|c|}{$\mathrm{CaSnSrO}_{3}$} \\
\hline Fotocatalisador & $500{ }^{\circ} \mathrm{C}$ & $800{ }^{\circ} \mathrm{C}$ & $1000{ }^{\circ} \mathrm{C}$ \\
\hline$\%$ de descoloração & 90,08 & 95,80 & 95,54 \\
\hline $\mathrm{K}\left(\mathrm{min}^{-1}\right)$ & 0,013 & 0,016 & 0,018 \\
\hline
\end{tabular}

As amostras de $\mathrm{SrSnO}_{3}$ dopado $1 \%$ mol de $\mathrm{Ca}$, apresentam uma eficiência média de remoção de corante em torno de $90 \%$, independente da temperatura. As amostras de $\mathrm{CaSrSnO}_{3}$, tratadas termicamente a $800{ }^{\circ} \mathrm{C}$ e $1000{ }^{\circ} \mathrm{C}$, 
apresentaram maiores valores de degradação. Novamente, os resultados de fotocatálise podem ser atribuídos aos defeitos estruturais e pelas fases secundárias, conforme observado na difração de raios X. A $500{ }^{\circ} \mathrm{C}$ não se observa picos de difração intensos o suficiente para dimensionar a porcentagem de fase, atribuída a cada plano cristalino presente no sistema, em função da própria limitação do equipamento (3-5\% de erro). Logo, não possível relacionar a contribuição destas fases à resposta fotocatalítica a $500{ }^{\circ} \mathrm{C}$.

Entretanto, para maiores temperaturas, ocorrem organização e ordenação de átomos, favorecendo a formação de fases, com picos de difração relativos a estas fases secundárias, como por exemplo, $\mathrm{O}_{\mathrm{SnO}_{2}}$. Para este material, a maior cristalinidade do sistema não foi capaz de alterar, significativamente, os resultados de fotocatálise. A reação segue a pseudo $1^{\text {a }}$ ordem e as constantes de velocidade foram próximas.

\section{Conclusões}

É possível concluir que o Método os Precursores Poliméricos foi eficiente para a obtenção dos materiais $\mathrm{SrSnO}_{3}$ puro e dopado com $1 \%$ de bário e $1 \%$ de cálcio. Os materiais foram utilizados na avaliação da atividade fotocatalítica do corante azul de metileno em função da temperatura de tratamento térmico. Todas as amostras apresentaram eficiência na degradação do corante. Com a adição dos dopantes, tem-se que os dois íons de interesse promoveram melhor estabilização da estrutura perovskita, $\mathrm{SrSnO}_{3}$, apresentando resultados melhores, quando comparado com o material sem a adição de dopante.

Observou-se que as amostras com mistura de fases apresentam desordem maior e, logo, melhor resultado na fotodegradação do corante. Dessa forma, é possível concluir que a fotocatálise está diretamente relacionada com a organização estrutural do material.

As amostras de $\mathrm{CaSrSnO}_{3}$, tratadas termicamente a 800 e $1000{ }^{\circ} \mathrm{C}$, apresentaram melhores resultados de fotodegradação, porém tratadas a $800{ }^{\circ} \mathrm{C}$ seriam a de melhor aplicação, ou seja, mais viável, devido à baixa de temperatura, e por consequência, gerar menores custos ao processo de obtenção dessa.

\section{Agradecimentos}

Agradecimento ao Instituto de Química da UFG/RC. Bolsas CNPq, CAPES e FAPEG.

\section{Referências}

1. Lucilha, A. C.; Takashima, K. Quím. Nova 2009, 32, 6. [CrossRef]

2. Jorge, I. R.; Tavares, F. P.; Santos, K. G. D.; Blucher Chemical Engineering Proceedings 2015, 2, 1. [CrossRef]

3. Scotti, R.; Lima, E. C.; Benvenutti, E. V.; Piatnicki, C.; Dias, S. L.; Gushikem, Y.; Kubota, L. T.; Quím. Nova 2006, 29, 2. [CrossRef]

4. Leal, P. V. B.; Gregório, A. M.; Otoni, E.; Silva, P. R.; Krauser, M. O.; Holzbach, J. C.; Journal of Biotechnology and Biodiversity 2012, 3, 4. [CrossRef]

5. Pignatello, J. J.; Oliveros, S. E.; Mackay, A.; Journal Critical Reviews in Environmental Science and Technology 2006, 36, 1. [CrossRef]

6. Pascoal, S.A.; Lima, C. A. P.; Sousa, J. T.; Lima, G. G. C.; Vieira, F. F.; Quím. Nova 2007, 30, 5. [CrossRef]

7. Oliveira. A.; Saggioro; E. M.; Pavesi, T.; Moreira, J.C.; vieira ferreira, L.F.; Molecular Photochemistry-Various Aspects 2012. [CrossRef]

8. Teixeira, C. P. D. A. B.; Jardim, W. D. F. Caderno temático UNICAMP: Campinas, 2003. [CrossRef]

9. Kunz, A.; Peralta-Zamora, P.; Moraes, S. G. D.; Durán, N.; Quím Nova 2002, 25,1. [CrossRef]

10. Fioravanti, C.; Velho, L.; Pesquisa Fapesp 2012, 198. [CrossRef]

11. Santos, H.; Silva, L. P. C.; Passos, F. B.; Rev.Virtual de Quimica 2015, 7, 4. [CrossRef]

12. Junqueira, A.C.; Carbonari, A. W.; Saxena, R. N.; Mestnik-Filho, J.; Dogra, R.; J. Phys. Condens. Matéria 2005, 17, 43. [CrossRef]

13. Cassia-Santos, M.; Mendes, S.; Gurgel, M.; Figueiredo, A.; Godinho Jr, M.; Braz, C.; Longo, E.; Cerâmica 2014, 60, 354. [CrossRef]

14. Nogueira, Raquel F.P.; Jardim, W. F.; Quim. Nova 1998, $21,1$. [CrossRef]

15. Oliveira, A. P. M.; Saron, A.; Rev. de Iniciação Científica, Tecnológica e Artística 2014, 4, 2. [CrossRef]

16. Eduardo, A. C.; Pereira, S. C.; Silva, P. D.; De Figueiredo, A. T.; Barrado, C. M.; Li, M. S.; Longo, E.; Advances in Applied Spectroscopy: Concepts and Techniques, 2017.[CrossRef]

17. Cullity, B. D.; Elements of X-ray diffraction, Addison: Wesley Mass, 1978. 
18. Gonçalves, R.; Castro, D.; Santos, M.; Figueiredo, A.; Barrado, C.; Leite, E.; Godinho Jr, M.; Cerâmica 2013, 59, 351.[CrossRef]

\section{Letícia G. Oliveira', Murillo H. M. Rodrigues ${ }^{1,2}$, Ariadne C. Eduardo ${ }^{1,3^{*}}$, Mario J. Godinho $^{1,3}$ \& Maria R. de C. Santos ${ }^{1}$}

1 UFG-Universidade Federal de Goiás, Unidade Acadêmica Especial de Química- RC, CEP 75.704- 020, Catalão, GO, Brasil

${ }^{2}$ UFSCAR-Universidade Federal de São Carlos, Programa de Pós-Graduação em Química, CEP 13565-905, São Carlos, SP, Brasil

3 UFG-Universidade Federal de Goiás, Unidade Acadêmica Especial de Física- RC, CEP 75.704- 020, Catalão, GO, Brasil

*E-mail: arycanedo@gmail.com 
